\title{
Research on Teaching Construction of the Special Practical Training Course of Computerized Numerical Control(CNC) Processing
}

\author{
Kui Jin \\ Dalian Vocational \& Technical College Dalian, China. \\ jk_810912@163.com
}

Keywords: Course construction; Practical teaching quality; Ability cultivation

\begin{abstract}
Based on the purpose of professional personnel cultivation, the status of profession cultivation pattern and the feedback from corporations, this research had a feasible and validating reform on profession cultivation pattern and obtained certain exploratory results through resource integration and utilization.
\end{abstract}

\section{Introduction}

This course, "Special training for Computerized Numerical Control(short as CNC) processing", is a compulsory professional training course serving majors as: CNC technology, machinery design and manufacture and mould, etc. This course, with automation equipment-CNC as its study subject, lecture the construction, operating principles and operation methods of CNC. Students are expected to obtain the ability and skill of operating CNC correctly, processing and programming parts with CNC after practical training.

Aiming at make students have a good command of CNC system, processing parts with CNC, analysis, process design, installation, commissioning and processing of parts, this course is a key specialized course using real products as carriers in relevant industries.[1]This professional, practical and open-ended course focus on systematic training of CNC processing and applying.

\section{The Necessity of Reform of Curriculum Teaching of Professional Personnel Training Mode}

According to the status of professional personnel training mode and feedback from corporations, we found that we had spent too much time in theoretical study in former CNC course, which coursed a low effectiveness of professional course teaching and a lacking of professional training time. In former teaching model, the practical teaching and theoretical teaching were difficult to integrate. ${ }^{[2]}$ Meanwhile, because the practical training had not earn a major role in curriculum, we had overemphasized the systematicness of the subject in curriculum, neglected the ability training of the students. ${ }^{[3]}$ This made our students in an embarrassed situation in adapting the needs of job market and acceptation from relevant industries. Therefore, the reform of professional training in CNC is necessary.

\section{The Objectives of Curriculum Teaching and Construction}

The objective of curriculum construction is to train high quality CNC technical personnel with a strong ability of application through making reasonable teaching content arrangements, scientific practical teaching method and the application of advanced teaching method. In teaching contents, we emphasize the harmony and unity between the advantage and the fundamentality. In teaching method, we motivate students to practice and participate initiatively. We also pay equal attention to practical teaching and theoretical teaching. We emphasize the practical and operational skills and the professional innovation ability of students, aiming at having distinctive teaching features and remarkable teaching effect. 
Through practical teaching, students can be familiar with the processing technology for CNC, obtain CNC cutting technology and comprehensive application ability. There are three specific abilities will be cultivated as followed:

(1) Professional ability. It is the basic ability of mastering professional knowledge and application of CNC. ${ }^{[4]}$ Students are expected to have the ability to analyze and evaluate the problems in the task on their own, evaluate the process and the final result, including the operation of CNC, characteristics of processing material, the selection of blade and measuring tools, the design and processing of products, etc. It is a basic skill that required by CNC post.

(2) Social ability. The ability to integrate into the social environment and interact with others, such as: Conversational skills, self-positioning in the cooperation of others. ${ }^{[5]}$ This is the teamwork ability in CNC post.

(3) The ability of self-development. By combination of professional skills of CNC and social ability, students can improve themselves by personal learning.

\section{The Train of Thoughts of the Course Teaching Construction Reform}

The train of thoughts of professional practical training of CNC is lean by the whole continuum of action, not the former subject system. The professional ability of CNC processing industry is used as a reference basis for developing teaching content.

In the CNC practical training program, case teaching, project teaching and problem related teaching are applied. The overall teaching purpose of the CNC practical training teaching is the operational ability of CNC processing. Through specific training programs, students are trained in a real production environment for comprehensive skills, which allows students to find, to think, to analyze and to solve problems by themselves and fully mobilize students' learning enthusiasm and initiative. By doing this, students can learn with questions and answer the questions by learning, therefore, the self-learning ability of the students will be improved.

Built up a Reasonable Special Training Teaching System of CNC. The Structure of Special Training Teaching System of CNC. The special training teaching system of CNC is formed by basic operation skill training and comprehensive operation skill training. The relations between them are as follow:

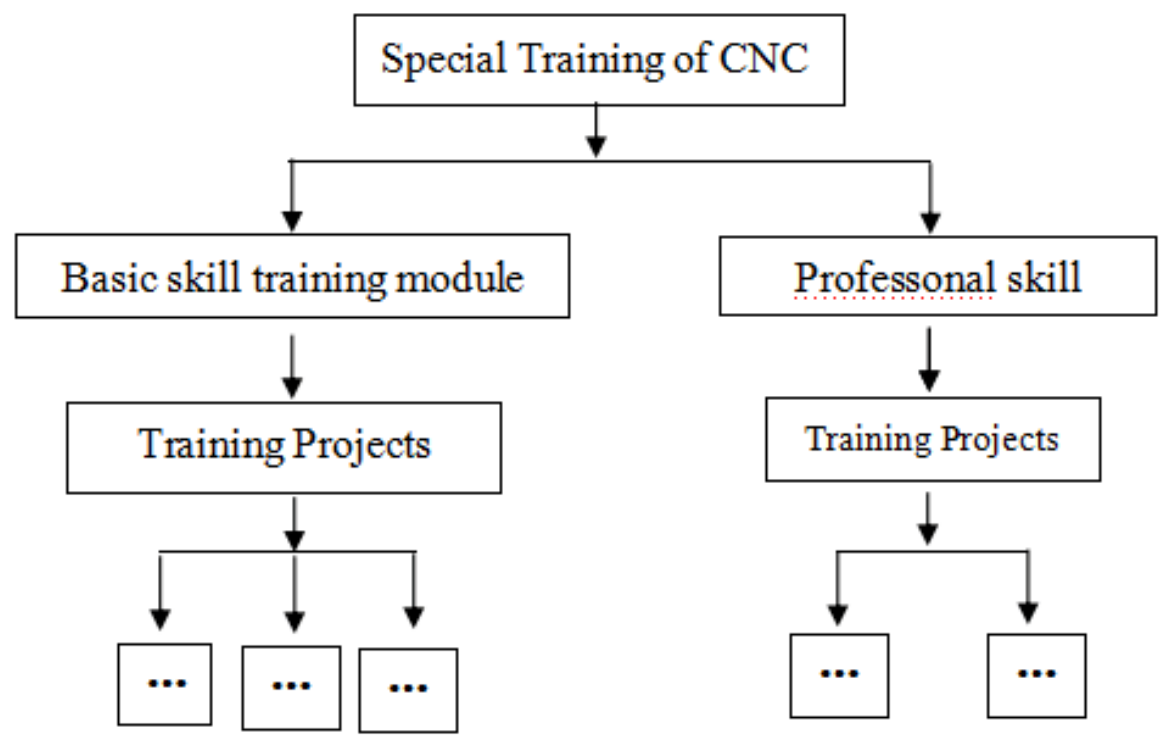

Figure 1 the structure of Special training teaching system of CNC

Organization Implementation Structure. The organization implementation structure is shown as Fig. 2. 


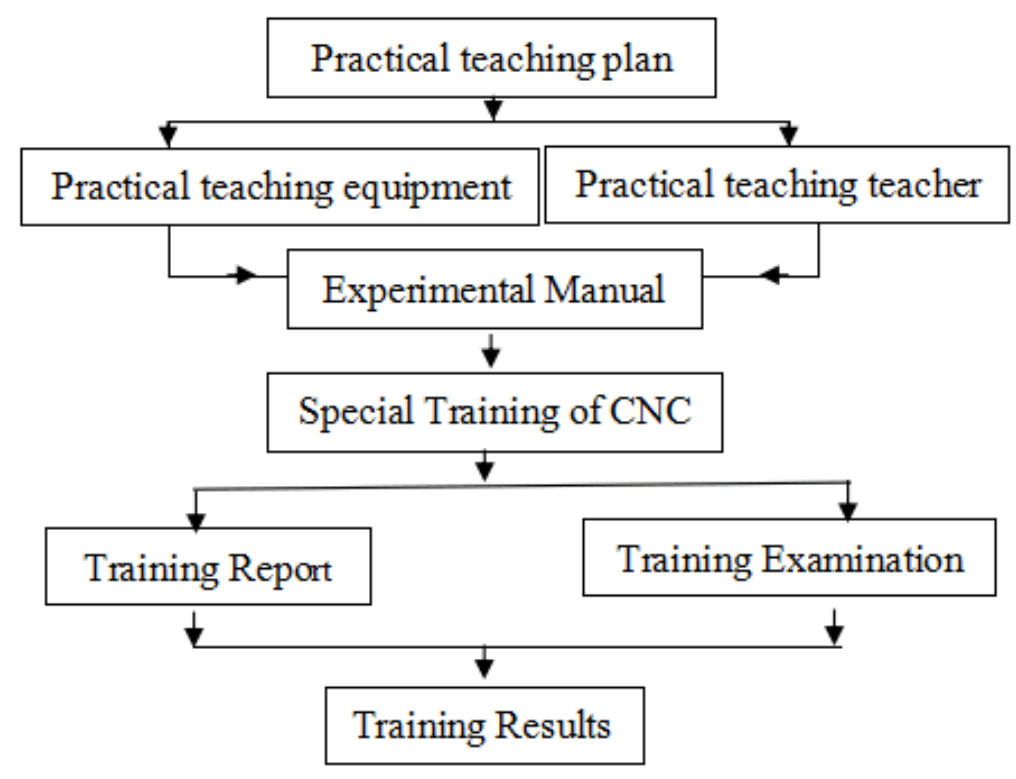

Figure 2 Organization implementation structure

Evaluation System of Special Training of CNC. Evaluation System of Special Training of CNC is shown as Fig. 3.

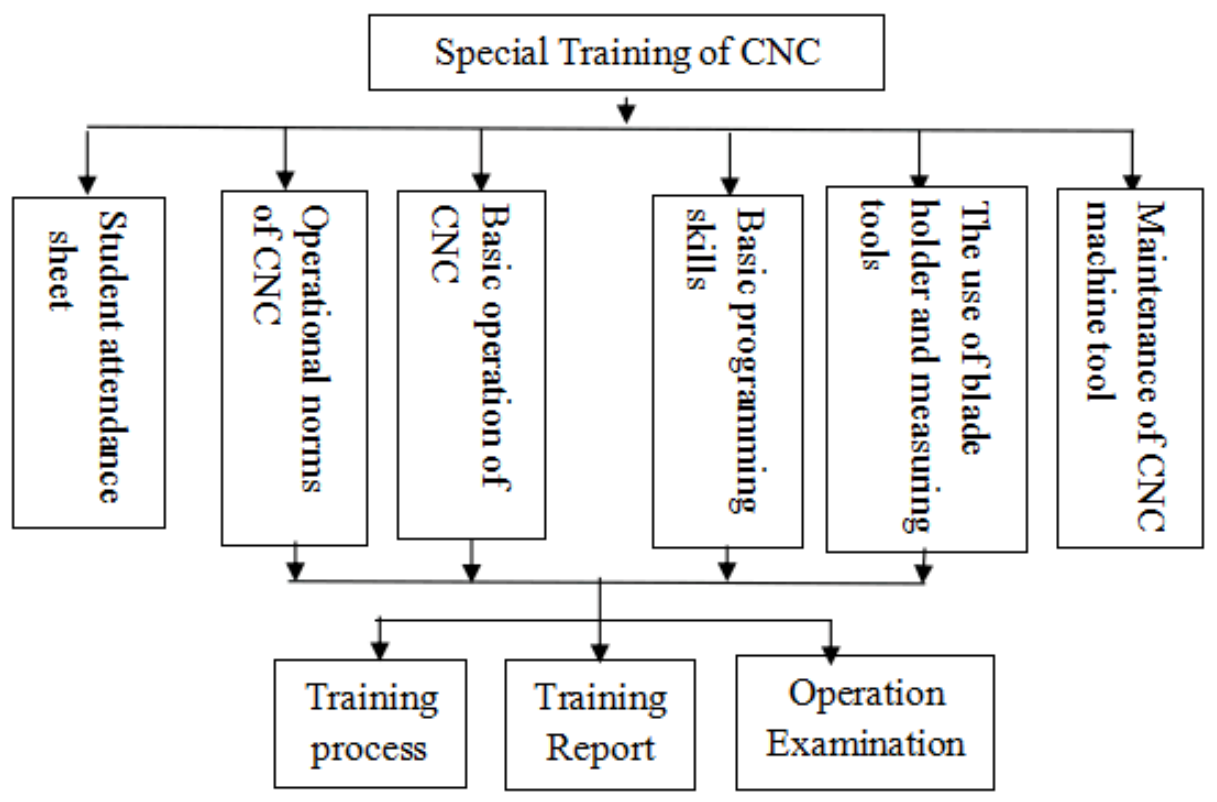

Figure 3 Evaluation System of Special Training of CNC

Formulate a Scientific and Reasonable Training Plan for CNC Turning. The training plan has two modules and the training time is one month at least. Each module has a clear training purpose, training content, procedures and requirements, assessment criteria and with indication of which module will be applied to which major. These modules are highly targeted and comprehensive, and the modules tend to be more large, so that students can design and process on their own. This plan has an outstanding practicality and can make the student really apply their knowledge.

Write a Detailed Training Guide for Our Teaching Equipment. Combining with the practical training plan, on the basis of sufficient demonstration, the actual training instruction of the corresponding module is prepared according to the current situation and training objectives of the university's equipment and each module strives to have comprehensive and outstanding practicality. The content of the layout is typical and operational and the process plan can exert the students' autonomous ability as far as possible. Through training in the training module, students can understand the overall working procedure of CNC, have a deep understanding of processing 
principle, the working process and programming method of CNC, the principle of developing the processing technology, which can let students adept quickly, operate with standard and have the ability to solve problems in real working post.

Formulate Scientific and Objective Evaluation Methods and Standards. Aiming at different majors, training subjects and training objectives, a scientific and objective evaluation method and annotation will be formulated and executed strictly by teacher according to the evaluation standard. Student's training results will be evaluated objectively and impartially and with regular summary and improvement.

\section{Conclusion}

Higher vocational college education, curriculum standards are an important part of implementing the teaching plan, carrying out the program of professional personnel training and implementing the training target. Teaching material is an important basis for teaching quality evaluation and evaluation of talent training in teaching management. It is also an guide book for assisting students to learn, the forming of the assessment standard. Through resource integration and development course construction reform, we have obtained some achievements, which is feasible and effective.

\section{References}

[1] Hua lijuan, Zeng jianwen. Teaching reform of CNC machining technology[J] Journal of Shanghai motor technical college. 2002

[2] Mechanical Industry Education Development Center, Center of national numerical control system engineering technology of huazhong university of science and technology, Research report on the teaching reform of numerical control talent demand and CNC professional education.

July, 2003

[3] Jinkui. Construction of CNC training program based on training students' ability of action, 2012.

[4] Xu Hao.Mechanical design manual [K]. mechanical industry publishing house ,2007.

[5] Liu Shouyong. Mechanical manufacturing technology and machine tool fixture [M]. Mechanical industry publishing house, 2008. 